\title{
Acquired Platelet Dysfunction with Eosinophilia
}

\author{
Emilio Villanueva III ${ }^{1}$ and Anna Marie Espaldon ${ }^{2}$ \\ ${ }^{1}$ Department of Pathology, College of Medicine, University of the Philippines - Manila \\ ${ }^{2}$ Department of Pediatrics, University of the East Ramon Magsaysay Memorial Medical Center, Quezon City, Philippines
}

ISSN 2507-8364 (Online)

Printed in the Philippines.

Copyright $(02020$ by the PJP.

Received: 30 April 2020.

Accepted: 19 June 2020.

Published online first: 22 June 2020.

https://doi.org/10.21141/PJP.2020.07

Corresponding author: Emilio Q. Villanueva III, MD, MSPH (Biostat), DPSP

E-mail: drevilthird@gmail.com

\begin{tabular}{|c|c|c|c|c|}
\hline Parameter & $\begin{array}{l}\text { Reference } \\
\text { Range }\end{array}$ & Units & $\begin{array}{c}\text { Initial } \\
\text { Consult }\end{array}$ & Follow-up \\
\hline \multicolumn{5}{|l|}{ Complete Blood Count } \\
\hline RBC Count & $4.00-5.20$ & $\times 10^{6} / \mathrm{L}$ & 4.54 & 4.78 \\
\hline Hemoglobin & $11.5-15.5$ & $g / d L$ & 12.0 & 12.4 \\
\hline Hematocrit & $35-45$ & $\%$ & 34.9 & 36.6 \\
\hline MCV & $75-87$ & $\mathrm{fL}$ & 76.9 & 76.6 \\
\hline $\mathrm{MCH}$ & $25-33$ & pg & 24.6 & 25.9 \\
\hline $\mathrm{MCHC}$ & $32-36$ & $\%$ & 34.4 & 33.9 \\
\hline RDW & $11.5-15.0$ & $\%$ & 13.8 & 12.8 \\
\hline Platelet Count & $150-450$ & $\times 10^{9} / \mathrm{L}$ & 179 & 338 \\
\hline PDW & $9.5-16.0$ & $\%$ & 13.3 & 9.0 \\
\hline MPV & $6.5-10.0$ & $\mathrm{fL}$ & 10.2 & 8.2 \\
\hline WBC Count & $5.0-14.5$ & $\times 10^{9} / \mathrm{L}$ & 8.46 & 8.46 \\
\hline Neutrophil & $32-54$ & $\%$ & 41.0 & 55.0 \\
\hline Lymphocyte & $28-48$ & $\%$ & 16.5 & 28.0 \\
\hline Monocyte & $3-6$ & $\%$ & 4.5 & 10.0 \\
\hline Eosinophil & $0-3$ & $\%$ & 36.0 & 6.0 \\
\hline Basophil & $0-1$ & $\%$ & 1.5 & 1.0 \\
\hline Absolute Eosinophil Count & $0-0.6$ & $\times 10^{9} / \mathrm{L}$ & 3.05 & 0.33 \\
\hline \multicolumn{5}{|l|}{ Coagulation Tests } \\
\hline PT & $8.7-11.5$ & sec & 10.2 & not done \\
\hline APTT & $31.8-43.7$ & $\sec$ & 35.6 & not done \\
\hline \multicolumn{5}{|l|}{ Platelet Function Tests } \\
\hline Bleeding Time (Ivy Method) & $2-8$ & $\min$ & 6.5 & not done \\
\hline \multicolumn{5}{|l|}{ Platelet Closure Time (PFA-100) } \\
\hline $\mathrm{Col} / \mathrm{Epi}$ & $82-150$ & sec & $>287$ & 104 \\
\hline Col/ADP & $62-100$ & $\mathrm{sec}$ & 115 & 70 \\
\hline
\end{tabular}

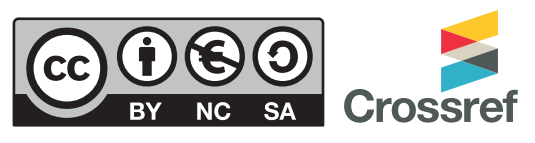

\section{INTRODUCTION}

A six-year-old male was brought in with 1-month history of recurrent spontaneous bruising which resolves without intervention. There was no history of trauma, other bleeding episodes, medication intake, nor recent viral infection. Birth, past medical, and family histories were unremarkable. Pertinent physical examination showed multiple, non-tender ecchymosis of varying chronicity and sizes on his upper and lower extremities and abdomen. The rest of the examination was essentially normal.

Initial laboratory work-up with complete blood count, prothrombin time, activated partial thromboplastin time, and bleeding time (Ivy Method) was done (Table 1). Peripheral blood smear examination showed eosinophilia and adequate qualitative platelet count. However, the platelet morphology shows numerous agranular and hypogranular grey platelets (Figure 1). Based on the history, physical examination, and initial work-up, acquired platelet dysfunction with eosinophilia (APDE) was suspected. Additional work-up with platelet closure time using Platelet Function Analyzer-100 (PFA100) was done (Table 1) which provides evidence of platelet dysfunction. No intestinal parasites were seen in three consecutive fecalysis done. Nonetheless, the patient was started on mebendazole. Subsequent followup after two months showed resolution of ecchymosis, eosinophilia, and platelet dysfunction (Table 1), with no noted recurrence.

APDE is a syndrome with transient state of platelet dysfunction mostly reported from children in Southeast Asia. ${ }^{1}$ APDE requires the following features for diagnosis: clinical manifestation of spontaneous ecchymosis on the trunk or extremities; hemogram showing eosinophilia; and evidence of platelet dysfunction. ${ }^{2}$ The spontaneous ecchymosis seen clinically is indistinguishable from that of idiopathic thrombocytopenic purpura (ITP). APDE is differentiated from ITP by the absence of thrombocytopenia. The eosinophilia observed may be an epiphenomenon seen in areas with endemic parasitism, since intestinal parasitism is the evident cause of eosinophilia. ${ }^{3,4}$ The platelet dysfunction is demonstrated by light transmission aggregometry, with results consistent with a platelet storage pool disorder., ${ }^{3,5}$ Alternatively, PFA may be used especially in pediatric patients since it requires less blood. ${ }^{2}$

However, platelet aggregation studies are offered only in specialized laboratories and it may take a few days before results are released. A presumed diagnosis can be 

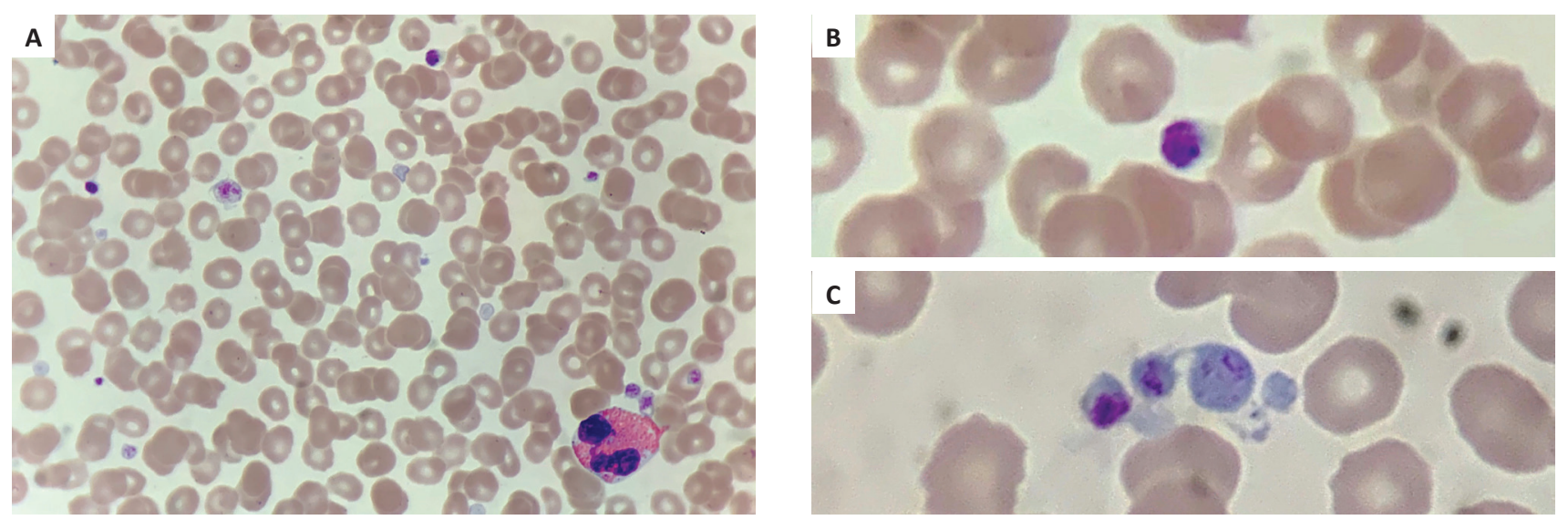

Figure 1. Peripheral blood smear photomicrograph showing an oil immersion field with an eosinophil, agranular grey platelets, hypogranular grey platelets, and a platelet with normal morphology (A) 1000X magnification; normal platelet (B) and three side-by-side platelets with decreasing granularity and a fourth agranular platelet (C), 3000X magnification.

made rapidly in any clinical laboratory offering routine hematology services, by microscopic examination of the platelet morphology. ${ }^{3}$ Wright stained blood smears show gray, pale staining platelets with smooth, round cell membrane contour. The cytoplasm may show fewer granules to none at all. Platelets with abnormal morphology may comprise about $30-80 \%$ of the platelets examined. This proportion correlates with the severity of the bleeding. ${ }^{6}$

The pathogenesis is still unknown. The platelet dysfunction has been thought to be due to the high production of $\mathrm{IgE}$ antibodies from a type I hypersensitivity reaction. The binding of immune complexes to platelets leads to in-vivo platelet activation. This activation promotes the release of adenine nucleotides, resulting in acquired storage pool deficiency. ${ }^{5-7}$

The prognosis is generally good, with a benign clinical course, and resolves spontaneously within 3 to 6 months to about a year. ${ }^{1,5}$

\section{STATEMENT OF AUTHORSHIP}

All authors certified fulfillment of ICMJE authorship criteria.

\section{AUTHOR DISCLOSURE}

The authors declared no conflict of interest.

\section{FUNDING SOURCE}

None.

\section{REFERENCES}

1. Yadav DD, Nayar PS, Manchanda RV. Acquired Platelet Dysfunction with Eosinophilia (APDE) syndrome: a case report. Indian J Hematol Blood Transfus 2016;32(Suppl1):S235-8. PMID: 27408400. PMCID: PMC4925510. https://doi.org/10.1007/s12288-0150554-X.

2. Shih MY, Wang RC, Liang CW, Wang JD. Acquired platelet dysfunction with eosinophilia in two patients. Pediatr Neonatol 2020;61(3):346-7. PMID: 32249099. https://doi.org/10.1016/j.pedneo.2020.03.004.

3. Lee AC. Acquired platelet dysfunction with eosinophilia or idiopathic purpura with grey platelets? Ann Acad Med. 2017;46(4):167-8. PMID: 28485465.

4. Zhou X, Ha SY, Ma SK, Lee TL, Chan GCF, Lau YL. Acquired platelet dysfunction with eosinophilia: report of two Cases. HK J Paediatr 2000;5:143-5. http://www. hkjpaed.org/pdf/2000;5;143-145.pdf.

5. Chotsampancharoen T, Sripornsawan P, Duangchu S, McNeil E. Clinical course and outcome of childhood acquired platelet dysfunction with eosinophilia. Acta Haematol. 2018;139(1):28-32. PMID: 29393084. https://doi.org/10.1159/000485790.

6. Isarangkura, P. Acquired platelet dysfunction with eosinophilia. In: International Hematology Society Meeting, Bangkok. 1999. http://citeseerx.ist.psu.edu/ viewdoc/download?doi $=10.1 .1 .621 .2041 \& \mathrm{rep}=$ rep 1 \&type=pdf. Accessed 13 Apr 2020.

7. Lim SH, Tan CE, Agasthian T, Chew LS. Acquired platelet dysfunction with eosinophilia: review of seven adult cases. J Clin Pathol. 1989;42(2):950-2. PMID: 2794084. PMCID: PMC501795. https://doi. org/10.1136/jcp.42.9.950.

Disclaimer: This journal is OPEN ACCESS, providing immediate access to its content on the principle that making research freely available to the public supports a greater global exchange of knowledge. As a requirement for submission to the PJP, all authors have accomplished an AUTHOR FORM, which declares that the ICMJE criteria for authorship have been met by each author listed, that the article represents original material, has not been published, accepted for publication in other journals, or concurrently submitted to other journals, and that all funding and conflicts of interest have been declared. Consent forms have been secured for the publication of information about patients or cases; otherwise, authors have declared that all means have been exhausted for securing consent. 